\title{
Fluid-assisted grain boundary sliding in bedding-parallel quartz veins deformed under greenschist metamophic grade
}

\author{
Leonardo Lagoeiro ${ }^{\mathrm{a}, *}$, Frank Fueten ${ }^{\mathrm{b}}$ \\ ${ }^{a}$ Departamento de Geologia, Universidade Federal de Ouro Preto, Ouro Preto, MG, 35400-000, Brazil \\ ${ }^{\mathrm{b}}$ Department of Earth Sciences, Brock University, St. Catharines, ON, Canada L2S $3 A 1$
}

Received 25 January 2007; received in revised form 17 October 2007; accepted 25 October 2007

Available online 1 November 2007

\begin{abstract}
Iron formation rocks of Quadrilátero Ferrífero, Brazil, were deformed at greenschist facies. Quartz grains in bedding parallel veins were sheared and deformed by a combination of mechanisms assisted by aqueous fluids. Veins in the outcrop appear to be stretched parallel to the compositional layering. The overall vein shapes resemble those of boundinage and pinch and swell. In thin sections, veins show microstructures similar to those observed in hand samples, where domains of large quartz crystals are pulled apart for several millimeters. The voids between quartz fragments are filled with domains of polycrystalline quartz. The microstructural and orientation data show that the strain imposed on the vein as a rigid and competent layer was not accommodated in the quartz polycrystals exclusively by crystal plastic deformation or dynamic recrystallization. The new grains are strain-free, with straight boundaries and with weak to random crystallographic fabrics. We interpret these features to have resulted from a combination of processes, which included grain boundary sliding accomplished by solution transfer. We propose that the coeval operation of both mechanisms allows the aggregate to deform at higher strain rates without necking of the vein layer in a type of flow similar to those described in superplastic regimes.
\end{abstract}

(C) 2007 Elsevier B.V. All rights reserved.

Keywords: Quartz microstructure; Quartz c-axis fabric; Grain boundary sliding; Solution transfer

\section{Introduction}

Rocks deformed at greenschist metamorphic facies show microstructures and crystallographic fabrics that reflect the operation of different deformation mechanisms (e.g. Knipe, 1989; Handy, 1990; Fitz Gerald and Stünitz, 1993) which are dependant upon a number of factors, such as temperature, pressure, fluid activity, composition and strain rates. Polyphase rocks composed of minerals with high contrasting mechanical properties are well suited to investigate the role of different deformation mechanism and their associated microstructures during progressive deformation. Deformation mechanisms that lead to grain size reduction can significantly alter the rheological behavior of rocks during progressive deformation and are linked to strain softening and the localization of

\footnotetext{
* Corresponding author.

E-mail address: lagoeiro@degeo.ufop.br (L. Lagoeiro).
}

deformation. If the temperature is high enough to enable climb of dislocations grain aggregates deformed by dislocation creep experience a reduction in grain size through progressive subgrain rotation recrystallization (e.g. Poirier and Nicholas, 1975; White, 1977; Guilopé and Poirier, 1979). The lower temperature equivalent of recrystallization mechanisms produces smaller grains and requires gradients in strain energy among grains in the grain aggregate for triggering grain boundary migration recrystallization (Poirier, 1985; Urai et al., 1986; Drury and Urai, 1990). However, there are aggregates deformed at low temperatures in which grain size reduction seems to be achieved by different mechanism. That is the case for quartz grains deformed by a combination of mechanisms involving intracrystaline plasticity (dislocation glide), microfracturing and solution transfer. In these aggregates fine-sized grains are originated by microfracturing and healing (van Daalen et al., 1999; Vernooij et al., 2006) or by precipitation and growth in small voids and microcracks (den Brok, 1992; Hippertt and Egydio-Silva, 1996). 
Iron formation rocks from Iron Quadrangle in Brazil (Quadrilátero Ferrífero, QF) provide good example to evaluate changes in deformation mechanism, microstructures and crystallographic fabrics during progressive deformation. The rocks are composed of iron oxide (magnetite and hematite in varied proportions) and quartz, phases of high contrasting mechanical properties. Deformed quartz veins that appear to have been stretched by structures similar to pinch and swell are embedded within a fine-grained matrix of magnetite and quartz grains. The stretched veins are characterized by fragments of coarse, plastically deformed quartz crystals, which are connected by a polycrystalline aggregate of nearly equant quartz grains. Crystallographic fabrics in the pinch and swell areas differ from those of the coarse grained veins. Using a combination of optical techniques the microstructures and the crystallographic orientation of single crystals and polycrystalline aggregates are examined to evaluate the spatial distribution and transition of deformation mechanism in those distinct fabric domains. We discuss the rheological implication of the transition of deformation mechanism and present a model for the development of fluid-assisted plastic flow in pure quartz aggregates of equant polycrystalline grains at greenschist facies metamorphism.

\section{Geological context}

Iron formations from Quadrilatero Ferrífero, Brazil (Fig. 1) are part of a meta-sedimentary sequence of volcanic-exhalative origin
(Dorr, 1969). The current thoughts are that these rocks were deposited in a shallow marine platform and their rhythmically alternation of iron oxide/silica rich layers resulted from intermittent volcanic exhalation and seasonal physico-chemical variation in depositional basin. The metasedimentary sequence of the Quadrilátero Ferrífero was regionally deformed by folding and transposition of the original compositional banding during the Transamazonian (2.0-1.7 Ga; Alkmim and Marshak, 1998) and Pan-African-Brasiliano orogenies (1.0-0.6 Ga; Chauvet et al., 1994). The deformation took place under regional metamorphism of greenschist to lower amphibolite facies (Herz, 1978; Pires, 1995). An extensive presence of aqueous fluid phase is indicated by the widespread presence of quartz veins associated with rich horizons of iron oxides (Lagoeiro, 1998) and phyllonitic rocks (Hippert, 1998). The intense folding and transposition of the original banding during the main deformation event (Transamazonic orogeny, referred as D1) resulted in a development of regional axial planar foliation $\left(\mathrm{S}_{1}\right)$ defined in iron formation rocks by a compositional banding. In outcrop the compositional banding has an anastomosing aspect typical of the shear zones. This is caused mainly by the presence of magnetite porphyroclasts which are surrounded by platy hematite and elongate quartz grains. S-C foliations, asymmetric strain shadows in magnetite porphyroclasts and asymmetrical isoclinal folds are consistent with a hanging-wall down movement (normal) sense of shear. Quartz veins of lens shapes were developed parallel to the compositional banding and are contemporary with the regional

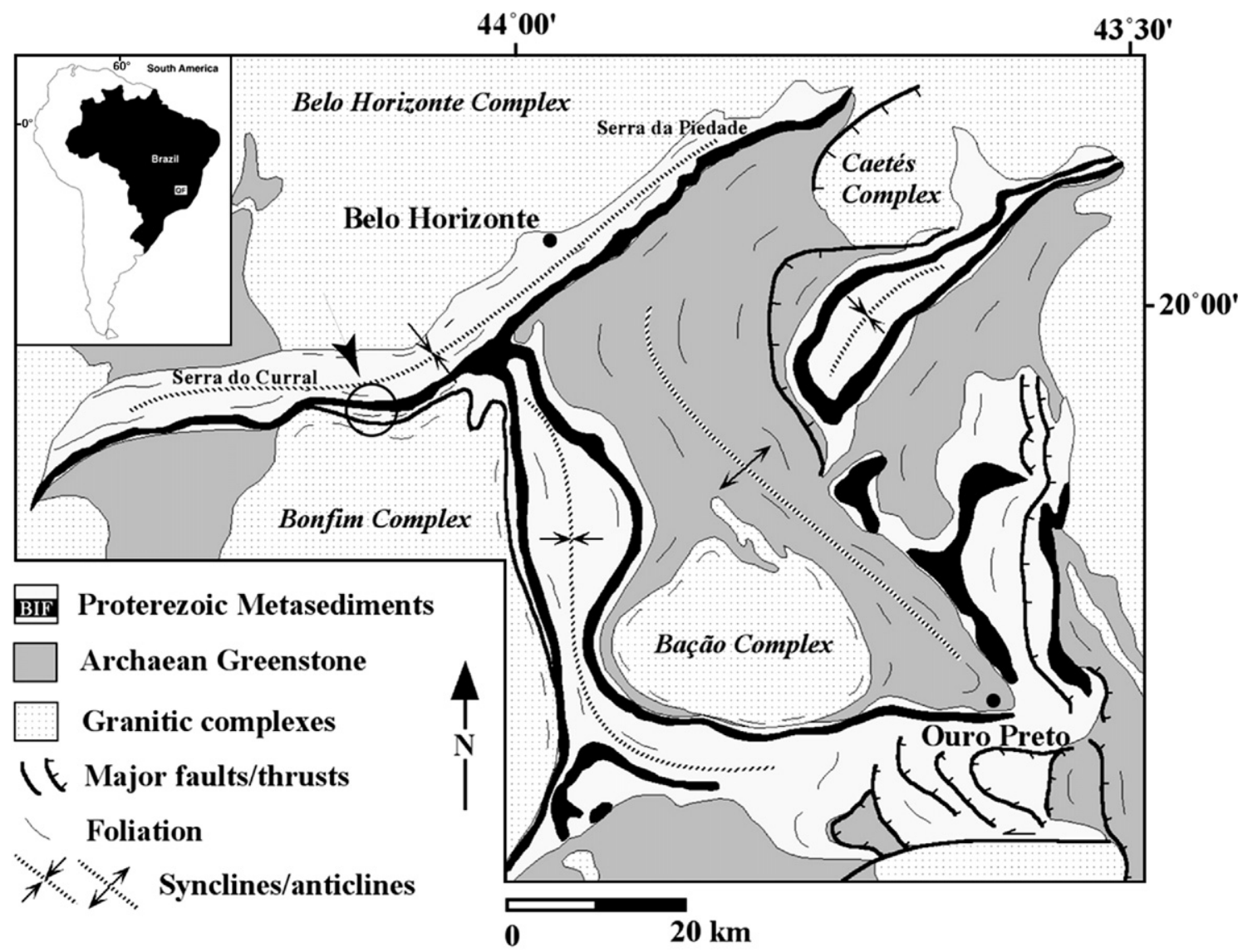

Fig. 1. Geological map of the Quadrilátero Ferrífero region (Dorr, 1969). Sampling site location is marked by a circle and an arrow. 
foliation $\left(\mathrm{S}_{1}\right)$. They are several millimeters in length that can be extended over the thin section width. Vein thickness varies from hundreds of micrometers to few millimeters.

\section{Analytical procedures}

Samples of bedding parallel quartz veins were oriented in the outcrop adopting the $X$-, $Y$-and $Z$-axes of the finite strain ellipsoid as a reference system. The $X$-axis is assumed to be parallel to the mineral elongation (maximum stretching), represented by elongate quartz and tabular crystals of hematite. The $Z$-axis, the maximum shortening direction, is assumed to be normal to the foliation and $Y$-axis is perpendicular to the $X Z$ section. All samples were sectioned parallel to $X Z$.

Thin sections were analyzed using a rotating polarizer stage (Fueten, 1997). Grain boundaries were obtained using the method presented by Fueten and Mason (2007), while quartz caxis were measured as outlined by Fueten and Goodchild (2001).

The grain boundary maps were obtained using the standard edge detection system in GeoVision (Fueten, 1997). An outline of the microstructures was also obtained by manual digitalization of photomicragraphs (Fig. 2). On the grain boundary map, the boundary segments that are attached to each nodal pixel (the pixel that connects a minimum of three line segment) are identified. Since the orientation of each boundary segment is known, the angle between adjacent boundary segments, or the intersegment angle can readily be calculated. The calculation of the aspect ratio and the orientation of the long axis of a grain are based on a common calculation of a best-fit-ellipse.

\section{Microstructures and crystallographic fabrics}

In outcrops as well as in thin sections two contrasting compositional domains can be distinguished: (1) the matrix and (2) pure quartz veins. The matrix (Fig. 2b, I) consists of a mixture of quartz and iron oxides which occur as granular crystals of magnetite and tabular hematite. The alignment of tabular hematite and elongate quartz crystals define an anastomosing foliation. Quartz veins parallel to the foliation are distributed throughout the outcrop, such that the alternation of light color pure quartz veins
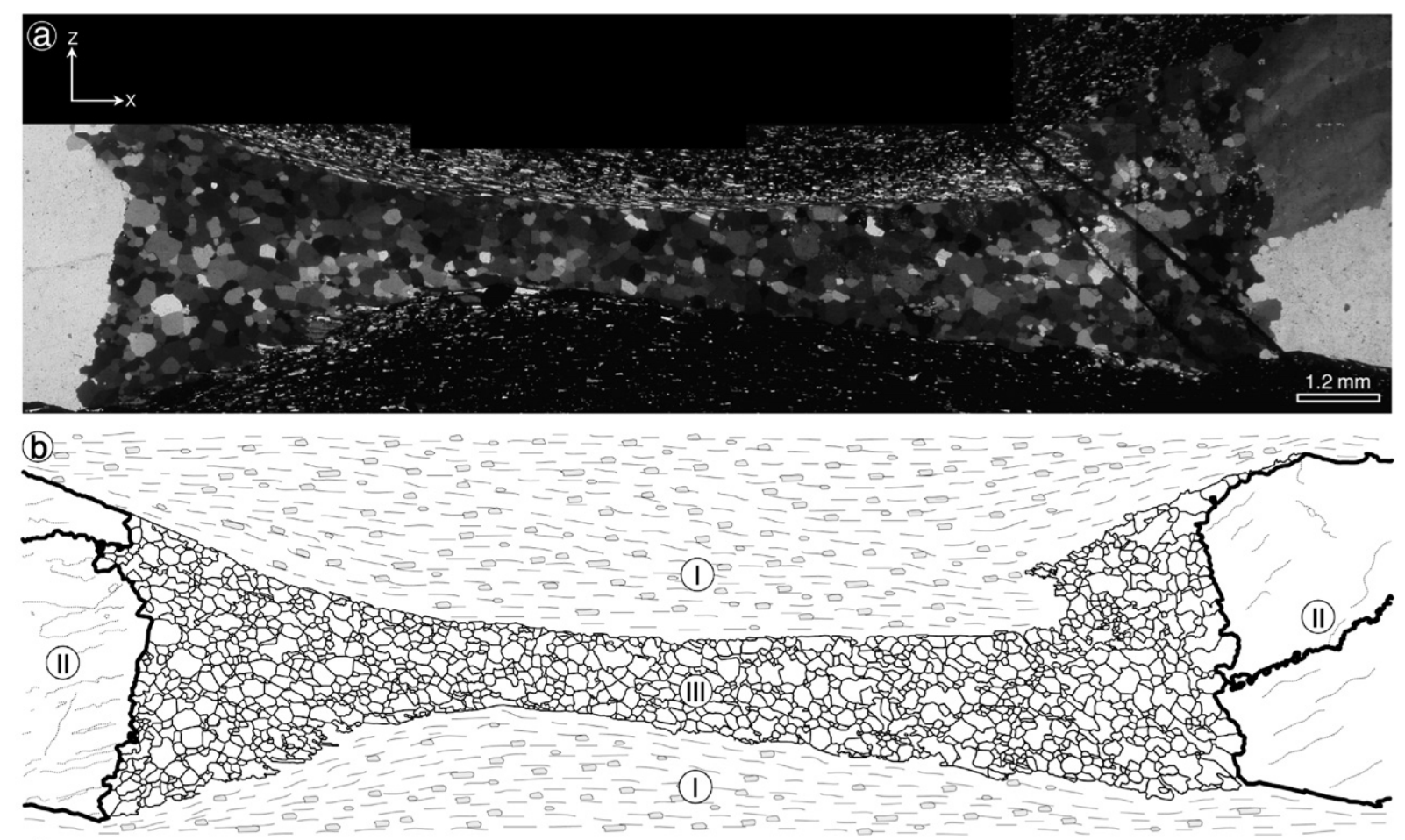

(C)

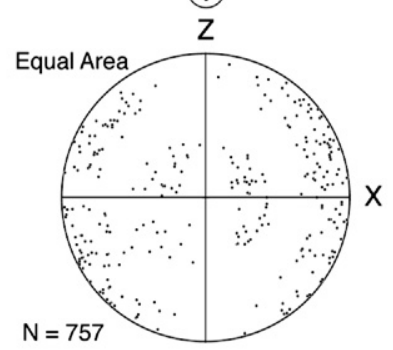

(II)

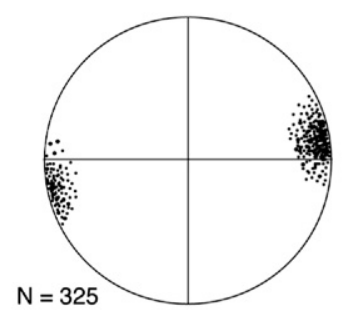

(III)

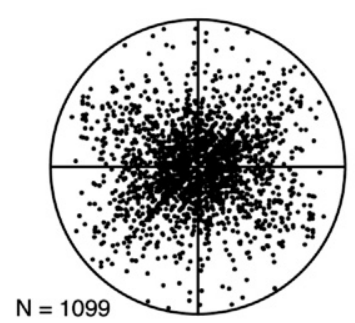

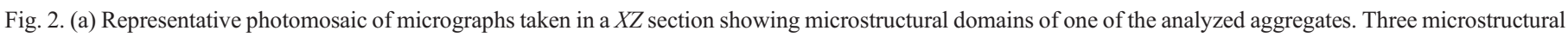

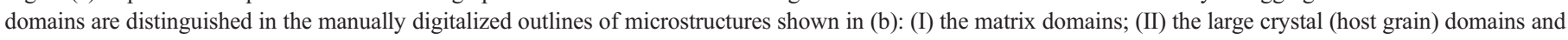
(III) the polycrystalline domains of nearly equant quartz grains. (c) Pole figures of $c$-axes measured by U-stage in each domain (I-III). 

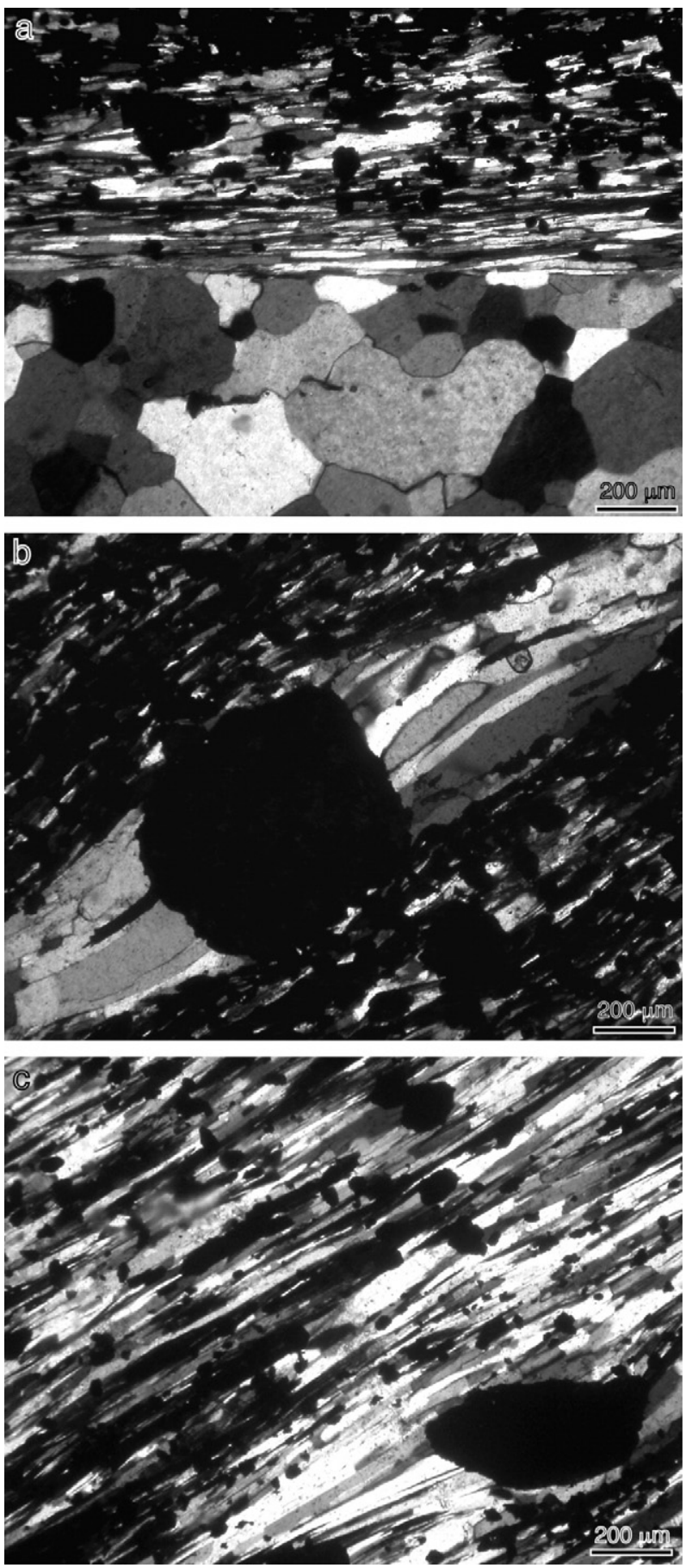

Fig. 3. Microstructures of matrix domains. (a) Fragments of magnetite porphyroclasts. (b) Asymmetric strain fringes around magnetite porphyroclast where quartz fibres were developed. (c) Elongate quartz grains in the matrix.

and the dark-colored matrix define a conspicuous compositional layering parallel to the metamorphic foliation. In thin sections, the overall appearance of the vein is that of boudinage or pinch-andswell (Fig. 2a and b). The microsctructures and crystallographic preferred orientations (CPO) of the matrix differ from those of the veins (Fig. 2c). The observed length of the "pinch" or "neck" regions in thin sections is close to $20 \mathrm{~mm}$ while veins extend beyond the area of the thin section and can be traced for $10-15 \mathrm{~cm}$ in the outcrop. Vein width also varies from approximately $1.25 \mathrm{~mm}$ in the "pinch" region to $3.75 \mathrm{~mm}$ outside it. Both the matrix and veins are discussed in more details below.

\subsection{The matrix}

The matrix consists of fragmented magnetite grains embedded in a foliated aggregate of hematite and elongate
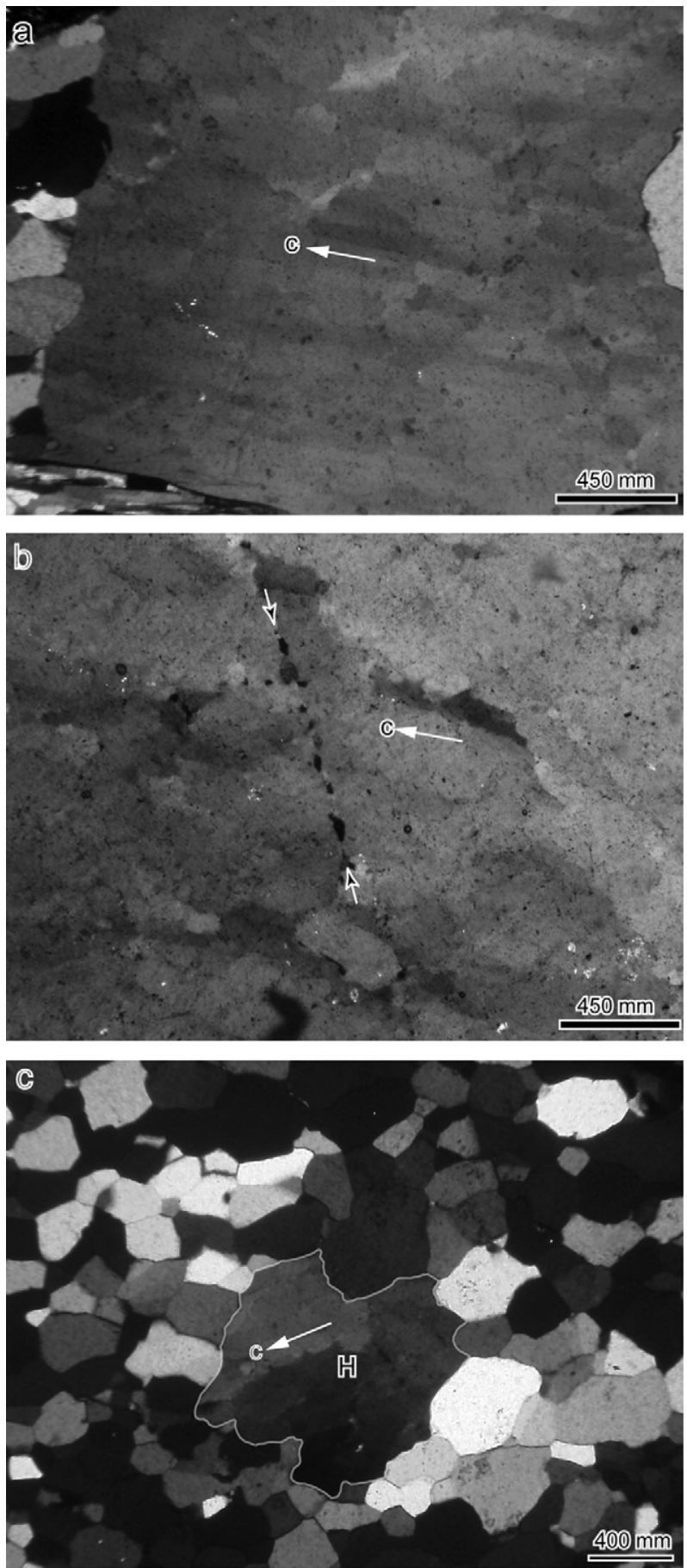

Fig. 4. Detail of the host grain domains showing subgrain microstructures. (a) Subgrain longest boundaries are oriented at $10^{\circ}-20^{\circ}$ to the foliation plane. (b) Healed fluid inclusions aligned parallel to the microfracture walls. (c) Remnant fragment of a large crystal $(\mathrm{H})$ immersed in a matrix of polycrystalline grains. 
quartz crystals. Magnetite fragments have varied shapes and sizes (Fig. 3a). In general, they are contoured by tabular to bladed hematite grains, giving the foliation an anastomosing aspect. Next to the magnetite clast asymmetric strain fringes are found (Fig. 3b). The strain fringes are composed mainly of quartz fibers. The same type of elongate quartz grains found in magnetite strain fringes is also present in the matrix. There, individual quartz grains are elongate (Fig. 3c). The size of the elongate quartz grains is variable, ranges from $100 \mu \mathrm{m}$ to $200 \mu \mathrm{m}$ in length and $10 \mu \mathrm{m}$ to $20 \mu \mathrm{m}$ width, with an average aspect $(X / Z)$ ratio of approximately 10:1. Most of the elongate quartz grains are optically strain free and the only sign of crystal plastic deformation shown by some of these grains is a slight undulatory extinction. Fluid and solid inclusions, mostly acicular opaque crystals, are commonly seen in fiber-shaped quartz grains. Long axes of acicular grains have the same shape orientation of the elongate quartz.

Besides the strong shape preferred orientation (SPO), elongate quartz grains have a strong crystallographic preferred orientation (CPO). Their $c$-axes (Fig. 2c, I) are preferentially distributed nearly to the foliation plane ( $X Y$ plane of the finite strain ellipsoid) and asymmetrically around the $X$-direction (macroscopic mineral lineation, L). Quartz fibers in strain shadows have similar $c$-axis fabrics.

\subsection{Bedding-parallel veins}

Bedding-parallel veins in the analyzed samples are composed of quartz grains with two distinct microstructures: large crystals (host grains or clasts; Fig. 2a and b-II) and smaller equant polycrystalline grains (new grains). The quartz vein on either side of the "pinch" region is composed of large ( $>5 \mathrm{~mm}$ diameter) crystals, while the quartz inside the "pinch" region is composed of a polycrystalline aggregate of smaller quartz grains.

\subsubsection{Large crystal domains}

Large crystals (Figs. 2a and 4a) in the bedding-parallel veins are fragmented by inclusion trails, indicative of healed microcracks (Fig. 4b). The overall shape of the fragments is very irregular (Fig. 4c). Internally quartz crystals show strong undulatory extinction and low angle boundaries (less than $10^{\circ}$ of mismatch) between subgrains, which are usually elongate with dimensions of approximately $300 \mu \mathrm{m}$ by $50 \mu \mathrm{m}$. The longest subgrain boundaries are parallel to the $c$-axes of the host grains, which are preferentially oriented $10^{\circ}$ to $20^{\circ}$ to the foliation plane, i.e. around the $X$-direction of the pole figure (Fig. 2c-II).

\subsubsection{Polycrystalline domains}

Quartz within the domains of the "pinch" regions (Fig. 2a,b-III and Fig. $5 \mathrm{a}-\mathrm{c})$ has a wide size distribution $(10 \mu \mathrm{m}$ to $300 \mu \mathrm{m})$ with average of approximately $125 \mu \mathrm{m}$ (Fig. 6a). Most grains are characterized by low aspect ratios (Fig. 6b) and a weak preferred orientation of their long axes parallel to the foliation (Fig. 6c). Grain boundaries are predominantly straight and meet at triple junctions with dihedral angles clustered about mean and median values of $119^{\circ}-120^{\circ}$ (Fig. 6d).
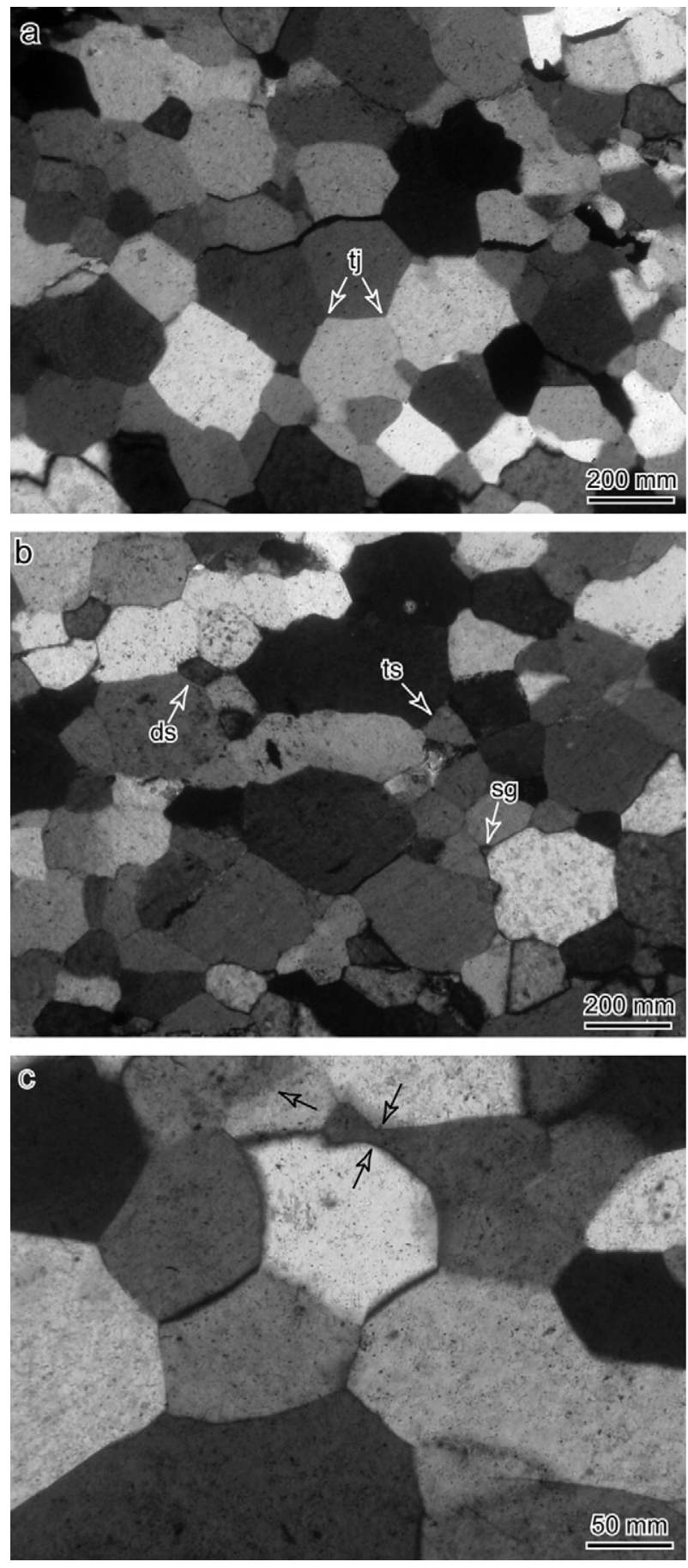

Fig. 5. Polycrystalline domains. (a) More or less equant polygonal quartz grains with straight boundaries meeting at $120^{\circ}$ (tj). (b) Small grains (sg) $(10-50 \mu \mathrm{m})$ at triple junctions of large grains. Triangular (ts) or diamond shapes (ds) of small grains predominate. (c) Some grain boundaries are extended into the triple junctions, as indicated by arrows on the photomicrograph.

Although grains have a wide size distribution, small grains in a range from $10 \mu \mathrm{m}$ to $50 \mu \mathrm{m}$ are mostly found at the triple junctions of larger grains and have triangular or diamond shapes with slightly curved boundaries (Fig. 5b). Some quartz boundaries are elongate into the triple junctions giving the extended boundaries a neck shape configuration (Fig. 5c). 
(a)

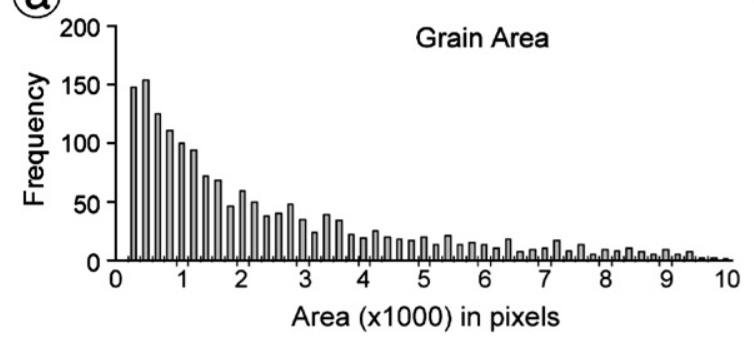

(b)

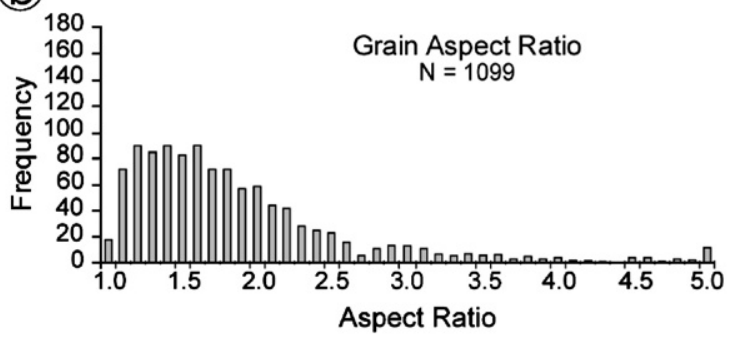

(C)

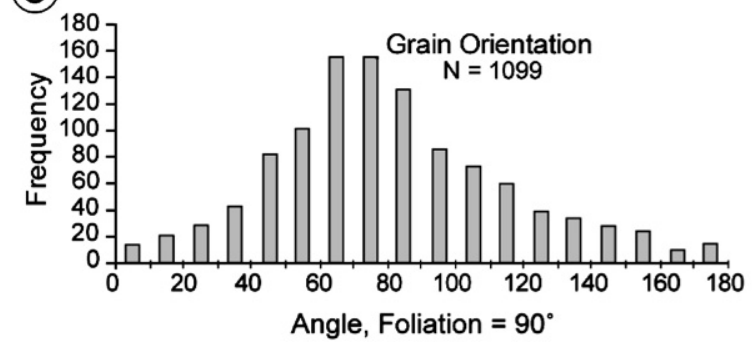

(d)

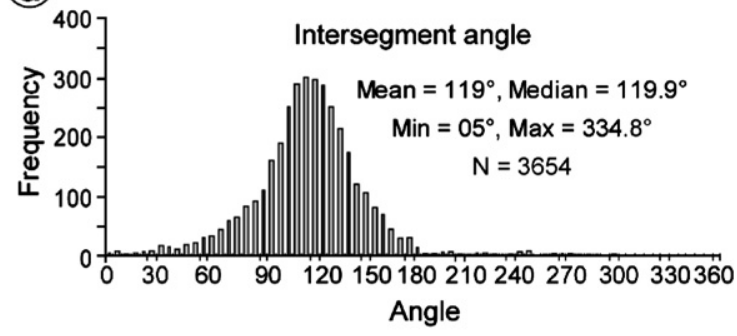

(e)

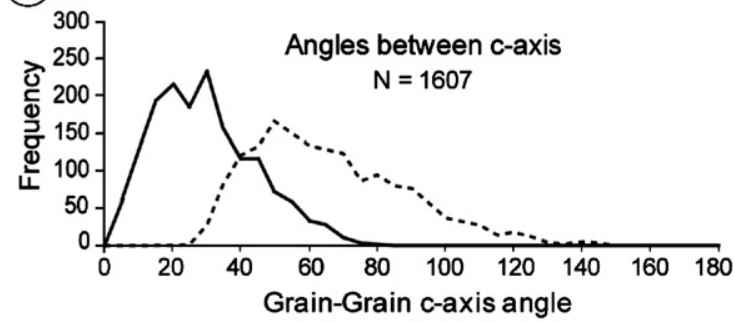

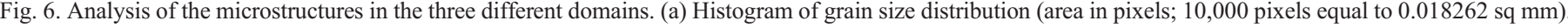

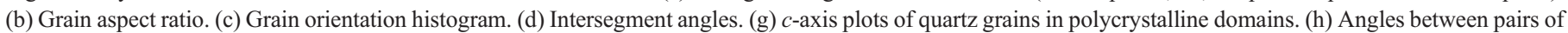
$c$-axes of neighboring quartz grains (misorientation angles).

Optically grains extinguish abruptly and do not have any internal microstructure indicative of crystal plastic deformation. Fluid or solid inclusions and inclusion trails are absent, in contrast to the large number of inclusions found in the host crystals.

The polycrystalline quartz aggregates do not show pronounced $c$-axis preferred orientations (Fig. 2c-III). There is a tendency for the $c$-axes to show some concentration around the $Y$-direction. But in general the $c$-axes are scattered around the center of the pole figure ( $Y$-direction). The misorientation angles between the $c$-axes of the old and the new grains are in a range of $20-50^{\circ}$ (Fig. 6e). The transition in orientation from the subgrains of single crystals to the new grains is abrupt with misorientation angles larger than $20^{\circ}$ (Fig. 7).

\section{Discussion and interpretation}

The low angle subgrain boundaries observed in the large crystals suggest a crystallographic control on the subgrain misorientation. This is indicative of lattice glide associated with dislocation creep, and subgrain forming recovery processes. In contrast, the polycrystalline grains within the pinch regions are largely devoid of evidence of crystal plastic deformation even though this region appears to have undergone extension.

\subsection{Microstructure in large crystals}

The microstructures and crystallographic orientations in the large crystals (host grains) are indicative of crystal plastic deformation. However, the $c$-axis orientations of these crystals close to the strain-X argues against a slip along basal planes. Host crystals might have been grown with their $c$-axes oriented around the $X$-direction. Later deformation might have led to a gradual lattice bending and formation of elongate subgrain boundaries $\left(<10^{\circ}\right)$ at high angle to the slip (basal) planes.

Similar $c$-axis orientations are found in elongate quartz grains in the matrix. Those grains are interpreted as a result of net dissolution and precipitation with elongate quartz grains growing with their $c$-axes parallel to the extension direction, resulting in strong $c$-axis maxima around the $X$-direction in the pole figure. Hippertt (1994) interpreted a similar $c$-axis fabric of elongate quartz in phyllonitic rocks as a result of dissolutionprecipitation creep. An origin for single quartz grains in the vein might be partially explained by a mechanism of dissolution- 


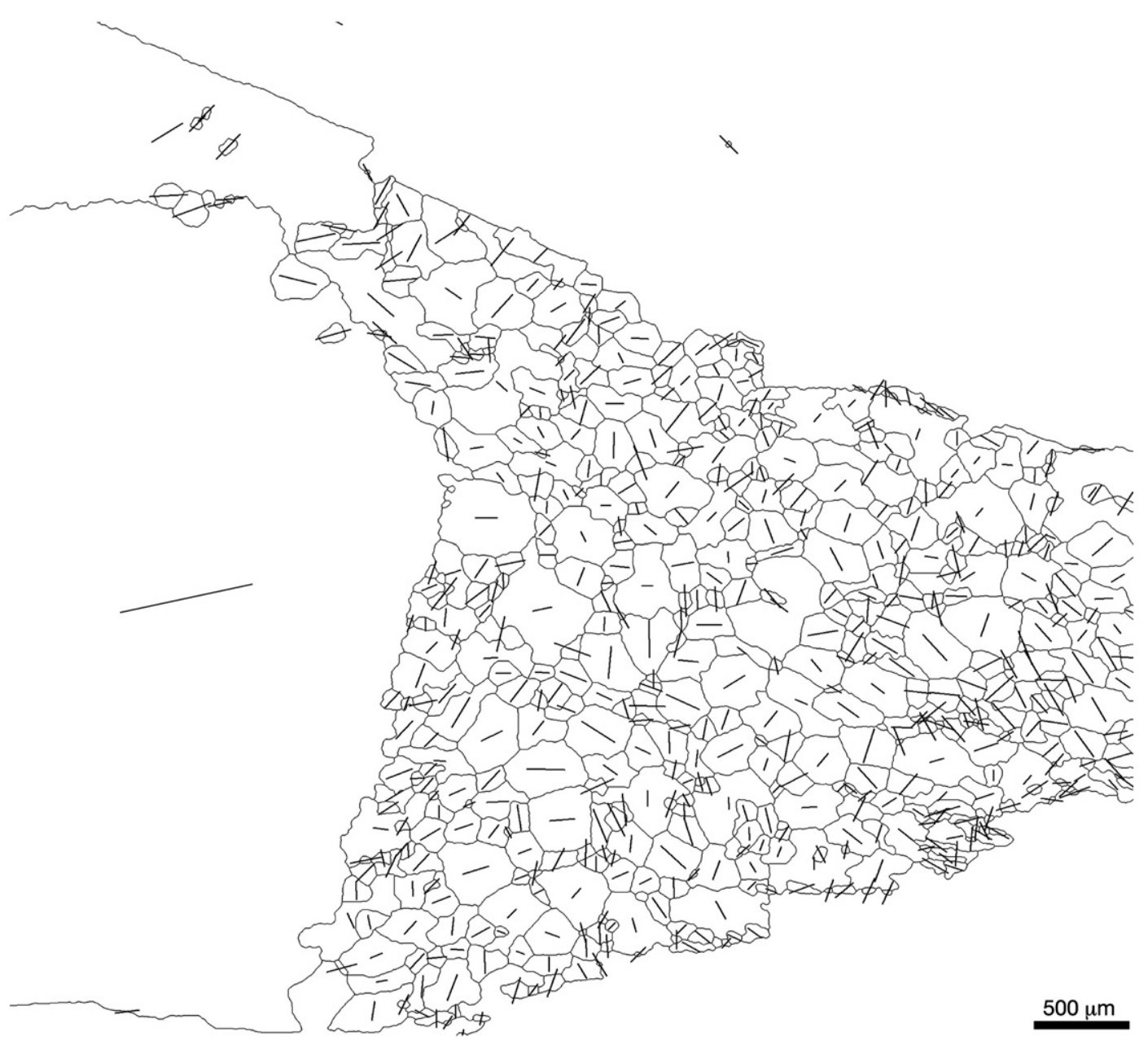

Fig. 7. Grain boundary outlines showing $c$-axis traces (straight lines) of the host and the new grains.

precipitation. These grains were subsequently deformed by dislocation glide and microfracturing.

\subsection{Microstructures of polycrystalline regions}

\subsubsection{Development of grains within the polycrystalline regions}

The transition from the large grains to the small grains is abrupt with clear distinct boundaries between the two domains and no region of intermediate grain size (Fig. 2; Fig. 4a and c; Fig. 7). There is a clear difference between the lattice deformation of large and small grains. The large grains have strong undulatory extinctions while the small grains do not. The grain boundaries of the small grains are predominantly straight and the mean and median intersegment angles are $120^{\circ}$. These are microstructures commonly interpreted as annealed or statically recrystallized. The crystallographic fabric within the polycrystalline regions is marked by a scattered distribution of $c$-axes around the center of the pole figure (Y-direction) and misorientation angles in average greater than $20^{\circ}$.

These features are not compatible with progressive subgrain rotation and we suggest that the majority of small grains also formed by precipitation. Some large grains immersed in the polycrystalline aggregates appear to be relict grains in a matrix of recrystallized aggregate. Subgrains observed within these large grains have sizes similar to the grains in the matrix. These features resemble a core-mantle-structure and might be used as an evidence for progressive subgrain rotation. However, the $c$-axis orientations of the old grains and subgrains match those of the single crystal in the swell domains and contrasts largely with the $c$-axis orientation of the new grain in the neighboring matrix (Fig. 4c). Therefore, it seems more likely that the polycrystalline regions may have formed initially as microfractures which continued to open as the vein pulled apart.

\subsubsection{Deformation within polycrystalline regions and rheological implications}

The overall pinch appearance of these regions suggests that the polycrystalline aggregate has undergone considerable stretching. This indicates a change in deformation mechanism from the crystal plastic deformation mechanisms operating within the large grains to those operating within the polycrystalline region.

We will argue that the main deformation mechanisms operating within the polycrystalline regions are grain boundary sliding and diffusive mass transfer and that the fabric despite its "static" or "annealed" appearance mostly represents a dynamic deformation fabric. While dislocation creep was certainly possible at the conditions of deformation, microstructures and CPOs within the aggregate is incompatible with deformation by crystal plastic mechanisms. 
We have presented ample evidence that fluid assisted solution and precipitation were operating within the matrix and the vein. Indeed, we argue above that new grains formed by precipitation. Thus the aggregate of new grains is most likely to be deformed under condition during which fluid-assisted diffusive mass transfer took place.

To accommodate the perceived stretching parallel to the foliation in the vein the most likely process appears to be grain boundary sliding (GBS), combined with fluid assisted mass transfer.

As it is evidenced by the lack of lattice deformation, the weak $\mathrm{CPO}$ and the high misorientation angle between neighboring grains (e.g. Bestmann and Prior, 2003) within the polycrystalline region, GBS is very efficient and would cause a softening of the polycrystalline aggregate, leading to an increase in rates of deformation or stress drops. A switch in deformation mechanisms from dislocation creep (large grain domains) to superplastic-like regimes (Ashby and Verall, 1973; Boullier and Gueguen, 1975; Schmid, 1982; Poirier, 1985; Rutter et al., 1994; Boulier and Gueguen, 1998; Hoshikuma, 1996) accompanied by dissolution-precipitation creep allows the aggregate to accommodate large strains without necking (boudinage) or fracturing. Minor shape changes resulting when crystals sliding past each other are accommodated by fluidassisted diffusive mass transfer as represented by flat grain boundaries parallel to the foliation (dissolution) and small triangular or diamond-shaped grains at new grain junctions (precipitation). Some grain boundary migration might also have occurred to prevent grain boundary cracks or voids. This could have been a subsidiary accommodation mechanism for grain boundary sliding as suggested by the presence of necked shaped or lobate grain boundaries at triple points.

The rheological weakening effect arising from the reduction of cohesive strength of quartz-quartz grain boundaries in the new grain domains might led to the localization of the flow in polycrystalline quartz aggregates (White, 1979; White et al., 1980; Tullis et al., 1990). The steady state conditions might have been achieved when the strain producing mechanism (GBS) was balanced with the accommodation mechanism (fluid-assisted DMT) enhancing the deformation in the new crystal domains. We also note that the apparent macro scale stretching visible in the pinch structure may not represent the true strain of the vein. If fluidassisted dissolution and precipitation are active, there is no requirement for the deformation of the vein to take place at constant volume. The grain boundary sliding model suggests that more sites of precipitation would open during the stretching than sites of dissolution. Hence the polycrystalline region likely served as a net sink for dissolved silica which implies that the current volume of the polycrystalline region is greater than the volume of the proto-vein.

\section{Summary and conclusions}

The microstructural and $c$-axis orientation data from host grains and new grains in the studied rocks suggest that:

(1) The difference between $c$-axis distributions in the three domains results from different deformation processes. In the matrix elongate quartz grains with $c$-axis maxima around the $X$-direction were formed by dissolution-precipitation creep. Grains in the pinch domains were also formed by precipitation out of solution but their $c$-axes did not develop a preferred orientation.

(2) Host grains, represented by fragmented quartz single crystals, are deformed by glide along basal planes. The $c$ axis orientations of the host and the elongate quartz grains in the matrix are very close suggesting that both types of grains may have their $c$-axis fabrics formed by similar processes. The transition from the CPO of single crystals to the polycrystalline new grains in the pinch domains is abrupt with large misorientation angles.

(3) Polycrystalline grains in the new grain domains have incompatible sizes with the subgrains in the host grain domains. It is unlike that these grains may have been developed from the subgrains in the host grain domains. The best explanation for their origin is precipitation out of solution in voids and microcracks created during the fracturing of host grains.

(5) The weak crystallographic preferred orientation and the poor match of $c$-axis between neighboring grains support the grain boundary sliding (GBS) as the dominant mechanism of deformation in the new grain domains. The lack of shape preferred orientation (SPO) of these grains also suggest that GBS must have been important rather than pressure solution, otherwise new grains would present a SPO, which is not observed.

(6) The switch in the deformation mechanisms, from a combination of dislocation glide and microfracturing in the host grains to a grain boundary sliding accommodate by fluid-assisted diffusive mass transfer, allows the new grain domains to accommodate large increases of strain. The strain softening caused by microstructural transformation and the deformation mechanism swift led to a localization of deformation in the polycrystalline domains allowing the vein to accumulate large strain rates without necking or boudinage in a deformation mode similar to those of superplastic regime.

(7) The possible effect of static recrystallization during annealing differs in the three domains. Host crystals (swell domains) show microstructures of deformation not altered by annealing process. In the matrix elongate quartz grains preserve microstructures of dissolutionprecipitation. However, in the pinches new grains show large grain sizes $(>300 \mu \mathrm{m})$ and straight boundaries meeting at $120^{\circ}$. These features may be, at least in part, a result of grain coarsening (normal grain growth) during a period of annealing.

\section{Acknowledgments}

We acknowledge Heather Racher for microfrabric data acquisition using GV program and Mike Lozon for assistant in the figures. Paola Ferreira Barbosa is also thanked for digitalization of microstructures as well as for $c$-axis measurement on the $\mathrm{u}$ stage. L. Lagoeiro is grateful for financial support by $\mathrm{CNPq}$ project 200968/2005-0. This project was partially funded by an 
NSERC discovery grant to F. Fueten. The manuscript was improved by thorough reviews of Bas den Brok and Holger Stünitz. We are also grateful to Andrés Villavicencio for the editorial handling.

\section{References}

Alkmim, F.F., Marshak, S., 1998. Transamazonian orogeny in the southern São Francisco Craton region, Minas Gerais, Brazil: evidence for Paleoproterozoic collision and collapse in the Quadrilátero Ferrífero. Precambrian Research 90, 29-58.

Ashby, M.F., Verall, R.A., 1973. Diffusion accommodated flow and superplasticity. Acta Metallurgica 21, 149-163.

Bestmann, M., Prior, D.J., 2003. Intragranular dynamic recrystallization in naturally deformed calcite marble: a case study by means of misorientation analysis. Journal of Structural Geology 25, 1597-1613.

Boullier, A.M., Guéguen, Y., 1975. SP-mylonites: an origin of some mylonites by superplastic flow. Contribution to Mineralogy and Petrology 50, 93-104.

Boullier, A.M., Gueguen, Y., 1998. Peridotite mylonite produced by superplastic flow. In: Snoke, A., Tullis, J., Todd, V.R. (Eds.), Fault related rocks - a photographic atlas. Princeton Unversity Press, New Jersey, pp. 592-593.

Chauvet, A., Faure, M., Dossin, I., Charvet, J., 1994. A three-stage structural evolution of the Quadrilátero Ferrífero: consequences for the Neoproterozoic age and the formation of gold concentrations of the Ouro Preto area, Minas Gerais, Brazil. Precambrian Research 68, 139-167.

den Brok, B., 1992. An experimental inverstigation into the effect of water on the flow of quartzite. Geologica Ultrajectina 95.

Dorr II, J.V.N., 1969. Physiographic, stratigraphic and structural development of the Quadrilátero Ferrífero, Minas Gerais, Brazil. United States Geological Survey Prof. Paper 641-A. United States Geological Survey 1-110.

Drury, M.R., Urai, J.L., 1990. Deformation-related recrystallization processes. Tectonophysics 172, 235-253.

Fitz Gerald, J.D., Stünitz, H., 1993. Deformation of granitoids at low metamorphic grade I. Reaction and grain size reduction. Tectonophysics 221, 269-297.

Fueten, F., 1997. A computer controlled rotating polarizer stage for the petrographic microscope. Computers and Geosciences 23, 203-208.

Fueten, F., Goodchild, J.S., 2001. Quartz c-axes orientation determination using the rotating polarizer microscope. Journal of Structural Geology 23, 895-902.

Fueten, F., Mason, J., 2007. An artificial neural net assisted approach to editing edges in petrographic images collected with the rotating polarizer stage Computers and Geosciences 33, 1176-1188.

Guilopé, M., Poirier, 1979. Dynamic recrystallization during creep of singlecrystalline halite: an experimental study. Journal of Geophysical Research $84,5557-5567$.

Handy, M., 1990. The solid state flow of polymineralic rocks. Journal of Geophysical Research 95, 8647-8661.

Herz, N., 1978. Metamorphic rocks of the Quadrilátero Ferrífero, Minas Gerais, Brazil. United States Geological Survey Professional Paper, p. 641-C.
Hippertt, J.F., 1994. Microstructures and $c$-axis fabrics indicative of quartz dissolution in sheared quartzites and phyllonites. Tectonophyses 229 , $141-163$.

Hippertt, J.F., 1998. Breakdown of feldspar, volume gain and lateral mass transfer during mylonitization of granitoid in a low metamorphic grade shear zone. Journal of Structural Geology 20, 175-193.

Hippertt, J., Egydio-Silva, M., 1996. New polygonal grains formed by dissolutionredeposition in quartz mylonite. Journal of Structural Geology 18, 1345-1352.

Hoshikuma, A., 1996. Grain growth and superplasticity; their implication to earth science. Journal of Geological Society of Japan 102, 232-239.

Knipe, R.J., 1989. Deformation mechanisms - recognition from natural tectonites. Journal of Structural Geology 11, 127-146.

Lagoeiro, L., 1998. Tranformation of magnetite to hematite and its influence on the dissolution of iron oxide minerals. Journal of Metamorphic Geology 16, 415-423.

Pires, F.R.M., 1995. Textural and mineralogical variations during metamorphism of the Proterozoic Itabira Iron Formation in the Quadrilátero Ferrífero, Minas Gerais, Brazil. Anais da Academia Brasileira de Ciências 67, 77-105.

Poirier, J.P., 1985. Creep of crystals: high-temperature deformation processes in metals, ceramics, and minerals. Cambridge University Press, Cambridge.

Poirier, J.P., Nicholas, A., 1975. Deformation-induced recrystallization due to progressive misorientation of subgrains, with special reference to mantle peridotites. Journal of Geology 83, 707-720.

Rutter, E.H., Casey, M., Burlini, L., 1994. Preferred crystallographic orientation development during the plastic and superplastic flow of calcite rocks. Journal of Structural Geology 16, 1431-1446.

Schmid, S.M., 1982. Microfabric studies as indicators of deformation mechanims and flow laws operative in mountain building. In: Hsu, K.J. (Ed.), Mountain building processes. Academic Press, London, pp. 95-110.

Tullis, J., Dell'Angelo, L., Yund, R.A., 1990. Ductile shear zones from brittle precursors in feldspathic rocks: the role of dynamic recrystallization. In: Hobbs, B.E., Heard, H.C. (Eds.), Mineral and Rock Deformation: Laboratory Studies (the Paterson Volume), 56. Geophysical Monograph of American Geophysical Union, pp. 67-81.

Urai, J.L., Means, W.D., Lister, G.S., 1986. Dynamic recrystallization of minerals. In: Hobbs, B.E., Heard, H.C. (Eds.), Mineral and Rock Deformation: Laboratory Studies (the Paterson Volume), 36. Geophysical Monograph of American Geophysical Union, pp. 161-200.

van Daalen, M., Heilbronner, R., Kunze, K., 1999. Orientation analysis of localized shear deformation in quartz fibres at the brittle-ductile transition. Tectonophysics 303, 83-107.

Vernooij, M.G.C., Kunze, K., den Brok, B., 2006. 'Brittle' shear zones in experimentally deformed quartz single crystals. Journal of Structural Geology 28, 1292-1306.

White, S.H., 1977. Geological significance of recovery and recrystallization processes in quartz. Tectonophysics 39, 143-170.

White, S.H., 1979. Grain and subgrain size variation across a mylonite zone. Contribution to Mineralogy and Petrology 70, 193-202.

White, S.H., Burrows, S.E., Carreras, J., Shaw, N.D., Humphreys, F.J., 1980. On mylonites in ductile shear zones. Journal of Structural Geology 2, 175-187. 